\title{
Open fetal surgery for myelomeningocele repair in France
}

Guilbaud Lucie ${ }^{a, b}$, Maurice Paul ${ }^{a, b}$, Lallemant Pauline ${ }^{b, c}$, De Saint-Denis Timothée $e^{b, d}$, Maisonneuve Emeline ${ }^{a, b}$, Dhombres Ferdinand ${ }^{a, b}$, Friszer Stéphanie ${ }^{a, b}$, Di Rocco Federico ${ }^{e}$, Garel Catherine ${ }^{b, f}$, Moutard Marie-Laure ${ }^{b, g}$, Lachtar Mohamed-Ali ${ }^{h}$, Rigouzzo Agnèsi, Forin Véronique $^{\mathrm{b}, \mathrm{c}}$, Zérah Michel $^{\mathrm{b}, \mathrm{d}}$, Jouannic Jean-Marie ${ }^{\mathrm{a}, \mathrm{b}}$

a. Sorbonne University, AP-HP, Trousseau Hospital, DMU ORIGYNE, Department of Fetal Medicine, 26 Avenue du Dr Arnold Netter, 75012 Paris, France.

b. National Reference Center for Rare Disease: Vertebral and Spinal Cord Anomalies (MAVEM Center), AP-HP, Trousseau Hospital, 26 Avenue du Dr Arnold Netter, 75012 Paris, France.

c. Sorbonne University, AP-HP, Trousseau Hospital, Department of Physical Medicine and Rehabilitation, 26 Avenue du Dr Arnold Netter, 75012 Paris, France.

d. Paris University, AP-HP, Necker Enfants Malades Hospital, Department of Pediatric Neurosurgery, 149 Rue de Sèvres, 75015 Paris, France.

e. Lyon Claude Bernard University, hôpital Femme-Mère-Enfant, Department of Pediatric Neurosurgery, 59 Boulevard Pinel, 69500 Bron, France

f. Sorbonne University, AP-HP, Trousseau Hospital, Department of Pediatric Radiology, 26 Avenue du Dr Arnold Netter, 75012 Paris, France.

g. Sorbonne University, AP-HP, Trousseau Hospital, DMU ORIGYNE, Department of Pediatric Neurology, 26 Avenue du Dr Arnold Netter, 75012 Paris, France.

h. Sorbonne University, AP-HP, Trousseau Hospital, DMU ORIGYNE, Neonatal Intensive Care Unit, 26 Avenue du Dr Arnold Netter, 75012 Paris, France.

i. Sorbonne University, AP-HP, Trousseau Hospital, Department of Anesthesiology, 26 Avenue du Dr Arnold Netter, 75012 Paris, France.

Corresponding Author: Lucie Guilbaud

Email address: lucie.guilbaud@gmail.com

Telephone: 0631823271

Address: Service de Médecine Fœtale, Maternité, Hôpital Armand Trousseau

26 avenue du Docteur Arnold Netter 75571 Paris cedex 12 


\title{
Highlights
}

- $59 \%$ of the children who had a MMC fetal repair had a hindbrain herniation reversal at birth

- $75 \%$ of the children who had a MMC fetal repair did not require a ventriculo-peritoneal shunt in the first year of life

- At age 3,75\% of the children who had a MMC fetal repair were able to walk with orthotics or independently and $100 \%$ attended school.

- Fetal surgery for MMC seems to have no benefit on children's sphincter functions.

\begin{abstract}
Introduction - Open fetal myelomeningocele (MMC) surgery is currently the standard of care option for prenatal MMC repair. We described the population referred to our center and reviewed outcome after open fetal MMC repair.
\end{abstract}

Material and methods - All patients referred to our center for MMC were reviewed from July 2014 to June 2020. For all the patients who underwent fetal MMC repair, surgical details, maternal characteristics and data from the neonatal to the three-years-old evaluations were collected.

Results - Among the 126 patients referred to our center, $49.2 \%$ were eligible and $27.4 \%$ $(n=17)$ of them underwent fetal MMC repair. Average gestational age at fetal surgery was $24^{+6}$ weeks. There was no case of fetal complication and the only maternal complication was one case of transfusion. We recorded $70 \%$ of premature rupture of membranes and $47 \%$ of premature labor. Average gestational age at delivery was $34^{+2}$ weeks and no patient delivered before 30 weeks. There was no case of uterine scar dehiscence or maternal complication during cesarean section. After birth, $59 \%$ of the children had a hindbrain herniation reversal. At 1 -year-old, $42 \%$ were assigned a functional level of one or more better than expected according to the prenatal anatomic level and $25 \%$ required a ventriculoperitoneal shunt. At 3year-old, all the children attended school and $75 \%$ were able to walk with orthotics or independently.

Conclusion - Open fetal surgery enables anatomical repair of the MMC lesion, a potential benefit on cerebral anomalies and motor function, with a low rate of perinatal and maternal complications.

Keywords: Fetal surgery; Myelomeningocele; Myeloschisis; Spina bifida; Open maternal fetal surgery; Dysraphism 


\section{Introduction}

Myelomeningocele (MMC) is the most common central nervous system congenital anomaly with a prevalence of 5.97 per 10,000 births in France over the last ten years [1]. This malformation results in life-long morbidity, including sensory and motor neurological deficits, sphincter disorders, and cerebral complications related to the Chiari 2 malformation and the potential associated hydrocephalus. In France, $90 \%$ of MMC are diagnosed by prenatal ultrasound, allowing precise parental counseling before birth $[2,3]$.

Ten years ago, the results of the multicenter prospective randomized Management of Myelomeningocele Study (MOMS) demonstrated that open fetal surgery improves children's prognosis, decreasing the rate of shunting at 12 months of age and increasing the rate of hindbrain herniation reversal and the ability to walk at 30 months of age [4]. Recently, MOMS investigators published their results on the follow-up of the children and demonstrated that the beneficial effects persist at school age [5]. Since the MOM study, fetal MMC repair has become an option for prenatally diagnosed MMC. Fetal surgery for MMC was introduced in France at Trousseau Hospital in 2014 for couples willing to continue the pregnancy (PRIUM study) [6]. The objective of our study was to review the perinatal outcome of fetal MMC repair and the postnatal outcome until the age of 3 years old in our population.

\section{Material and methods}

\subsection{Recruitment and study population}

This cohort study reviewed the outcome for patients with open fetal surgery for myelomeningocele repair between July 2014 and June 2020 in our tertiary university maternalfetal medicine center. Consent was obtained from the parents and the study was approved by our Institutional Review Board (approval 13048, Clinical Trial registration NCT01983345) for the 10 first cases. Since 2018, open fetal surgery is offered as conventional care. Maternal demographics, prenatal diagnostic criteria, fetal surgery, delivery, neonates and children outcomes were documented prospectively in our fetal MMC repair database.

Each patient referred to our center for fetal dysraphism was evaluated in a standardized way by fetal sonography and fetal MRI prior to comprehensive prenatal counseling [6]. All the ultrasound examinations and fetal MRI were performed by an experienced pediatric radiologist (CG). Prenatal counseling was conducted jointly by a 
specialist in Maternal Fetal Medicine (MFM) and a pediatric neurosurgeon. A consultation with a psychologist was offered to each couple and all patients were evaluated by an anesthesiologist. After a reflection time, couples were reviewed by the MFM specialist in order to give their final decision.

Inclusion criteria for fetal MMC surgery were singleton pregnancy, gestational age before 26 weeks of gestation, MMC with the upper level located between T1 and S1, evidence of hindbrain herniation, maternal age of at least 18 and body mass index $(\mathrm{BMI})<35 \mathrm{~kg} / \mathrm{m}^{2}$. Exclusion criteria were additional fetal malformations unrelated to MMC, fetal abnormal karyotype, severe fetal kyphosis, high risk for preterm delivery (previous preterm delivery, short cervix length measurement), uterine malformation, previous hysterotomy in the active uterine segment, placenta praevia, active vaginal bleeding, maternal HIV, hepatitis B or hepatitis $\mathrm{C}$ positivity and maternal contraindication to general anesthesia or surgery. Fetal ventriculomegaly, abnormal corpus callosum, perinodular heterotopia and abnormal gyration were not considered as exclusion criteria [7].

\subsection{Surgical procedure and postoperative management}

Patients were admitted to hospital the day before the surgery for preanaesthetic evaluation. Pre-operative medication consisted in Hydroxyzine dichlorhydrate (1 mg/kg), given one hour before the surgery. After a fasting period of eight hours, the patient was taken to a standard obstetrical operating room. Cephazolin ( $2 \mathrm{~g}$ intravenously) was given preoperatively. A lumbar epidural catheter was placed before the general anesthesia to allow a multimodal postoperative analgesia. Indomethacin and atosiban were used as perioperative tocolysis. Indomethacin was given as a $50 \mathrm{mg}$ per rectum (PR) preoperatively, followed by $50 \mathrm{mg}$ PR every six hours for the first 24 hours following surgery, and $25 \mathrm{mg}$ every six hours on the second day. Atosiban was given intravenously (IV) at the beginning of the surgery with a dosage of $18 \mathrm{mg} / \mathrm{h}$ during the three first hours, followed by an IV perfusion of $6 \mathrm{mg} / \mathrm{h}$ during 43 hours. After a preinduction preoxygenation, induction was performed using a rapid sequence (propofol, succinylcholine). Maintenance of anaesthesia was obtained using inhaled sevoflurane $3 \%$ and atracrium $0.5 \mathrm{mg} / \mathrm{kg}$. The opioid used in our center was sufentanil with a dosage of $0.2 \mathrm{mcg} / \mathrm{kg}$. In case of maternal hypotension, neosynephrin and ephedrine were used for preservation of utero-placental flow. A close maternal monitoring was maintained during the surgery including: heart rate, respiratory frequency, $\mathrm{O} 2$ saturation, electrocardiogram, body temperature, bispectral index, neuromuscular function monitoring, invasive arterial blood pressure, and measurement of input and output as a sign of volume status. 
Gravid uterus was exposed by a Pfannenstiel laparotomy and exteriorized. Fetal position, placenta localization, and umbilical cord insertion were then mapped by ultrasound examination. A hysterotomy of $6 \mathrm{~cm}$ was performed as described by Moron et al. (fig.1) [8]. Three Monocryl 0 full-thickness sutures were placed on each side of the future hysterotomy. Entry was progressively performed, and Allis forceps were positioned on the cut edges of the myometrium in order to expose the amniotic membrane. The membrane was then opened using scissors, under direct visualization. Two vascular forceps were placed on both sides to secure the membrane and the myometrium before the enlargement of the hysterotomy using electrocautery. One Vicryl 0 stitch was positioned at each end of the hysterotomy and a fullthickness Vicryl 0 running suture was performed to encircle the entire incision. A second running suture was performed around uterine opening with Monocryl 4-0 to secure the membrane to the inner portion of the myometrium.

The MMC repair was performed by the neurosurgeons according to a standardized protocol with multilayer closure including neurulation of the placode, under magnification using a Leica surgical microscope, as previously described [6]. The uterus was closed in two layers. The first layer consisted in a Vicryl 0 running suture involving the amniotic membrane and the inner portion of the myometrium. Before the last sutures were placed, warmed sterile saline with antibiotics (Vancomycin $500 \mathrm{mg}$ ) was used to restore amniotic fluid volume to preoperative level. The second layer consisted in a Vicryl 0 running suture involving the myometrium and the uterine serosa. The uterus was then put back into the abdominal cavity and the laparotomy closed in a standard fashion.

After surgery, patients were transferred to an intensive care unit for the first 72 hours of postoperative care [6]. The epidural catheter was removed on the third postoperative day. Patients were then transferred to the high-risk pregnancy obstetrical ward. All patients stayed in hospital five to seven days and were discharged with a prophylactic anticoagulation prescribed for two weeks, an oral analgesic medication if needed, and a maintenance tocolytic therapy (oral nifedipine) prescribed until 36 weeks.

At the time of discharge, patients were encouraged to stay near our center until cesarean delivery at 37 weeks of gestation. When this was impossible for the patients, they returned home, and delivery was scheduled at their local tertiary centers. 


\subsection{Follow-up during pregnancy and delivery management}

Patients were monitored weekly with a maternal and fetal clinical examination performed by a midwife at home, and a follow-up was scheduled every two weeks with a MFM specialist in our center. Comprehensive ultrasonography was performed for assessment of amniotic fluid index, cerebral ventricular dimension, hindbrain herniation, biparietal diameter, head circumference, femur length, abdominal circumference and placenta. Corticosteroids were used only in case of preterm rupture of membranes (PPROM) or preterm labor prior to 34 weeks. Each patient was scheduled for elective cesarean delivery at 37 weeks of gestation or earlier for standard obstetrical indications.

\subsection{Children's follow-up from birth to 3-year-old}

At birth, a complete clinical examination was carried out by a neonatologist and a transfontanellar ultrasound examination was performed within the first week. Each child was evaluated at birth, 1 month, 1 and 3 years by a multidisciplinary team including a pediatric neurosurgeon, a specialist in pediatric physical medicine and rehabilitation, and a pediatric orthopedist. All children were evaluated on the basis of standardized physical and neurological examination. The 1-month, 1-year and 3-year evaluations also included a cerebral and spinal cord MRI in order to assess hindbrain herniation, cerebral ventricles size, other cerebral anomalies, syringomyelia and spinal cord anomalies. In case of ventricular dilatation, intermediate cerebral MRI was performed.

The following data were collected at birth: Apgar score at 5 minutes, birth weight [9], head circumference [9], appearance of the MMC scar, presence of foot deformities, length of neonatal hospitalization, complications related to prematurity, and cerebral and spinal cord imaging observations.

At 1-year-old, the neurologic functional level was recorded as well as the cerebral and spinal cord imaging observations. The following data on urological functions were collected: presence of urinary incontinence during crying, urinary infections since birth, and renal and urinary tract ultrasound findings. Constipation was defined as a Bristol stool scale type 1 or type 2. The need for surgical or medical therapy including ventriculo-peritoneal shunt, orthopedic surgery, anticholinergic or laxative treatments was also recorded.

At 3-year-old, the same data were recorded. The pediatricians also noted if the child was attending school and additional details on urinary function (need for urinary intermittent catheterization, use of diapers) and bowel function (constipation, existence of anal leakage, need for rectal enemas). 


\section{Results}

\subsection{Population}

During the study period, a total of 126 patients were referred to our center for a suspicion of fetal MMC (fig.2). Of these patients, the diagnosis of MMC was revised in 32 cases: 11 cases of Limited Dorsal Myeloschisis (LDM), 20 cases of Mye-LDM and one case of lipomyelomeningocele [10,11].

In our cohort, 32 patients were excluded from the fetal surgery program due to: prenatal diagnosis of MMC after 26 weeks $(n=7)$, severe fetal kyphosis $(n=7)$, other associated anomalies unrelated to MMC $(n=3)$, twin gestation $(n=3)$, high risk for preterm delivery $(n=2)$, MMC with a S2 upper level $(n=4), B M I>35(n=2)$, placenta praevia $(n=1)$, history of severe preeclampsia $(n=1)$, maternal contraindication for surgery (maternal Ehlers Danlos syndrome, $\mathrm{n}=1$ ), and fetal potential contraindication for anesthesia (paternal history of malignant hyperthermia, $n=1)$.

Among the 62 eligible patients, the parents opted for termination of pregnancy in 40 cases (65\%). Among the 22 couples who decided to continue the pregnancy, 17 (77\%) opted for fetal surgery and $5(23 \%)$ opted for a postnatal conventional repair. Both maternal and fetal characteristics are presented in table 1. In the fetal surgery group, L5/S1 was the most common MMC level (53\%) and there was one case of thoracic MMC (6\%). One fetal surgery case presented with a diastematomyelia with a right T12 hemi-myelomeningocele and a bone spur extended from T12 to L3.

\subsection{Fetal surgery}

The median gestational age at the time of fetal surgery was $25^{+5}$ weeks (range: $21^{+1}-26^{+0}$ weeks). Four patients (24\%) had the fetal surgery before 24 weeks. Placental location was anterior in 13 cases $(77 \%)$. The median total operative time from maternal skin incision to closure was 188 minutes (range: 160 - $235 \mathrm{~min}$ ) with a median neurosurgical operative time of 55 minutes (range: $22-88 \mathrm{~min}$ ). In all cases, it was possible to close the defect without using artificial material or relaxing incisions. One mother required a blood transfusion postoperatively ( 2 units of red packed cells). No other maternal complications were observed during the surgery. There were no cases with maternal pulmonary edema in the peri-operative period. No fetal complication was observed during the surgery. 


\subsection{Maternal and obstetrical outcomes}

PPROM occurred in $71 \%$ of cases and preterm labor, in $47 \%$ (table 2 ). Among the 12 patients who had a PPROM, five presented a preterm labor. For one patient, a preterm labor associated with a hyperleukocytosis and an increased C-reactive protein led to the suspicion of chorioamnionitis and an emergency cesarean section was performed at $32^{+6}$ weeks. This mother was treated with amoxicillin clavulanate for seven days and did not develop any infection. Her neonate was not infected.

Thirteen patients delivered at Trousseau Hospital and four in their local tertiary center. The median gestational age at delivery was $34^{+2}$ weeks and none of the patients delivered before 30 weeks. The hysterotomy scar was thin in three cases (18\%) and no case of hysterotomy scar dehiscence was observed in our cohort.

\subsection{Neonatal outcomes}

There were no cases of intrauterine fetal demise or neonatal demise (table 3). The median birthweight was $2235 \mathrm{~g}$ (range: $1680 \mathrm{~g}-2980 \mathrm{~g}$ ). The median of hospitalization duration for neonates was 20 days (range: 5 - 60) and no severe complications related to prematurity (including grade 3 to 4 intraventricular hemorrhage, severe cerebral parenchyma hemorrhage, periventricular leukomalacia, ulceronecrotizing enterocolitis, and severe bronchodysplasia) were observed.

No cases of MMC scar dehiscence nor Cerebral Spinal Fluid (CSF) leakage were observed at birth. A reversal of the hindbrain herniation was observed in 10 out of the 17 cases (59\%) at birth. The five cases with corpus callosum anomalies detected on birth imaging (four cases of splenium agenesis and one case of anterior agenesis) were all diagnosed prenatally [7]. Five neonates presented heterotopias on birth imaging including two cases with normal pre-operative fetal MRI at $22^{+2}$ and $23^{+2}$ weeks.

At birth, 12 neonates $(71 \%)$ presented foot deformities, with seven cases with bilateral clubfoot (prenatal MMC level: L3, L4, L5 and S1), four cases with bilateral talus (MMC level: L5 and S1) and one case with right clubfoot and left vertical talus (MMC level: L3). Among these 12 cases, 6 had a normal feet examination at the second trimester ultrasound. These 6 cases had a MMC level of L5 or S1. The five neonates with no foot deformity at birth had a MMC level of T12 (case with a diastomatomyelia), L1, L2, and L5 (two cases).

\subsection{Outcome at 1 -year-old}


Among the 12 children who are at least 1-year-old at the time of writing, a ventriculoperitoneal shunt was indicated in three cases $(25 \%)$ at 3,6 , and 9 months respectively because of an increased occipital-frontal circumference associated with clinical signs of intracranial hypertension (table 4). Of the remaining 9 children, 8 had ventricular measurements greater than $15 \mathrm{~mm}$ but no clinical symptoms of intracranial hypertension. One child $(6 \%)$ required surgery to perform a tethered cord release at 9-months of age.

Neurologic functional level at 1-year-old was better than expected according to the anatomic MMC level in 5/12 children (42\%) (fig.3). Two children (17\%) underwent Achilles tenotomy and eight $(67 \%)$ required orthosis. Nine children $(75 \%)$ presented a urinary incontinence when crying and one child (8\%) had a neurogenic bladder requiring an anticholinergic treatment. Three children (25\%) had signs of neurologic colon with a Bristol score of 1 or 2 . In our center, osmotic laxative treatment is usually initiated at an early age in children with MMC, and $58 \%$ of our cohort were receiving osmotic laxatives at 1-year-old.

\subsection{Outcome at 3-year-old}

Eight children in our cohort have reached the age of 3 years old (table 5). There were no other cases of shunt than the three previously described and none of the children required a spinal cord surgery. All children attend school. Six children (75\%) had a better neurologic functional level than the one expected according to the anatomic level (fig.3). Among the eight evaluated children, $6(75 \%)$ were able to walk, including $5(83 \%)$ with orthotics and $1(17 \%)$, independently. The orthotics were ankle-foot orthosis, not requiring upper limb support, for 4 children, and a Hip-Knee-ankle-foot orthosis, requiring upper limb support, for 1 child.

Regarding urinary function, only one child was voiding volitionally. Four children $(50 \%)$ required urinary intermittent catheterizations and three (38\%) were in diapers. Four children $(50 \%)$ were treated with anticholinergic medication. Regarding bowel function, two children (25\%) had normal stools without treatment and one (13\%), with osmotic laxatives. Three children (38\%) had constipation, and two children (25\%) had constipation associated with intermittent anal leakage. Among the eight children, six (75\%) were treated with osmotic laxatives and three of them also required daily transanal irrigation. 


\section{Discussion}

Our study confirms that open fetal surgery enables anatomical repair of the MMC lesion in all cases with a low rate of perinatal and maternal complications since the median gestational age at delivery was $34^{+2}$ weeks, without any cases of severe complications related to prematurity.

\subsection{Efficiency of open maternal fetal surgery}

In our study, reversal of hindbrain herniation was recorded in $59 \%$ of cases at birth. This result is close to those of Moldenhauer et al. and Moron et al. $[8,12]$. The rate of hindbrain herniation reversal after open fetal surgery varies from $36 \%$ to $94 \%$ depending on the studies [4,8,12-14]. Although our results confirm that MMC fetal surgery can provide a hindbrain herniation reversal, it is difficult to conclude on the chances of success since there is a disparity in diagnostic methods of hindbrain herniation (ultrasound vs MRI) and children's age at evaluation, ranging from birth to 4-years-old depending on the studies.

At 12 months of age, we recorded $25 \%$ of ventriculo-peritoneal shunt. This low proportion represents another argument to offer fetal surgery to couples who intend to continue the pregnancy. Indeed, as several other groups, we have observed a decrease in the need for ventriculoperitoneal shunts of about $50 \%$ between the prenatal surgery group and the postnatal surgery one [4,15]. This result from fetal surgery is important because hydrocephalus and its surgical treatments have a significant impact on the patient's life with extremely frequent complications. Bowman et. al, in a series of 71 patients, report that $95 \%$ of them required at least one revision of the shunt, with some patients having up to 10 revision surgeries [16].

In our group, the shunt rate was particularly low, but it should be compared to our ratio of shunt in post natal repairs of MMC which is $46 \%$ (personal data). It is likely that our indications for CSF derivation are different from those of the other teams. In our study, $89 \%$ of the children had a ventriculomegaly greater than $15 \mathrm{~mm}$ at the age of 1 year but did not require derivation given their absence of symptoms.

In our cohort, we observed a better neurologic functional level than the one expected according to the anatomic level in $42 \%$ of children at 1 -year-old, and $75 \%$, at 3 -year-old. Although these results appear to be better than those of the MOM study, they should be interpreted considering the prenatal MMC level $[4,17]$. In our population, more than $50 \%$ of the fetuses had a MMC level of L5/S1 while $70 \%$ of the MOMs population had a MMC level higher than L5 $[4,16]$. However, this improvement of motor function is of importance 
considering that children with a functional level lower than L2 will potentially be able to ambulate independently, most often with braces support [18].

Our results show that despite fetal surgery, the vast majority of children with MMC present sphincter disorders. These results regarding the urological outcome of children prenatally operated are consistent with other studies $[19,20]$. Thus, Brock et al., from the MOM study cohort, are the only ones suggesting a potential benefit of prenatal surgery compared to postnatal surgery on volitional voiding and need for clean intermittent catheterizations and anticholinergic medication [21]. To our knowledge, no studies have yet investigated the potential benefit of MMC fetal surgery on bowel function.

Finally, the most important benefits provided by fetal surgery are represented by reversing the hindbrain herniation, preventing from the need for a ventriculoperitoneal shunt and improving motor function. However, care must be taken as to how the information about fetal surgery efficiency is disseminated during family counseling and parents should be informed that these benefits are not observed in all cases.

\subsection{Risks associated with open maternal fetal surgery}

In our cohort, we observed a particularly high rate of PPROM $(71 \%)$, higher than the one observed in the MOM study (46\%), despite a similar gestational age at birth $\left(34^{+2}\right.$ weeks vs $34^{+1}$ weeks) [3]. Several hypotheses could be discussed to explain this higher rate of PPROM.

First, the high level of PPROM could be related to a longer operating time. We recorded a longer total duration of surgery and a longer duration of neurosurgery than others $[4,8,12,22]$. This prolonged operating time is essentially due to the fact that we do not use a uterine stapling device to perform the hysterotomy. We made this choice assuming that the risk of dehiscence of the uterine scar was lower with a manual technique rather than using the stapler. Although the size of our study is limited, no cases of hysterotomy scar dehiscence have been observed. Our results are in line with the results observed in 237 cases reported by Moron et al., using the same technique to perform hysterotomy [8]. Thus, their uterine scar dehiscence rate was $3.8 \%$ whereas this rate ranges from $7 \%$ to $13 \%$ in the six other studies $[4,12-14,22,23]$. This complication of open fetal surgery is particularly important, especially since Goodnight et al. reported a uterine rupture rate of $9.6 \%$ in the subsequent pregnancy in a study including 77 pregnancies after open maternal-fetal surgery for MMC using a uterine staple device [23].

Two studies conducted by the MOM study investigators showed that nulliparity, early gestational age at surgery ( $<24$ weeks) and chorioamniotic membrane separation after fetal surgery were significant risk factors for subsequent development of PPROM [22,25]. The 
relatively small size of our cohort did not allow us to make this analysis. However, we recorded a low proportion of nulliparous women (24\%) and a low proportion of patients operated at early gestational ages.

Fetoscopy is one of the approaches considered to reduce maternal morbidity [26,27]. This technique may also allow vaginal delivery and will probably limit the risks for subsequent pregnancies [28]. The results of the fetoscopic technique are heterogeneous among the studies, particularly with regard to the rate of PPROM (25\% to $67 \%$ ), the operative duration (98 to 480 minutes), the gestational age at birth (32.5 to 37.7 weeks), the need for postnatal treatment of repair site ( $25 \%$ to $36.4 \%$ ), and the need for placement of a cerebrospinal fluid shunt within 12 -months ( $0 \%$ to $100 \%)$. It is therefore still difficult to conclude on a similar benefit compared to open surgery.

In our study, no cases of maternal pulmonary edema were recorded. This can be explained both by the use of atosiban rather than magnesium sulfate as perioperative tocolysis and by a restricted intraoperative hydration. American centers use magnesium sulfate as a tocolytic because atosiban does not have U.S. Food and Drug Administration approval for the prevention of premature delivery. In a study including 456 patients treated with magnesium sulfate for preterm labor, Wilson et al. recorded $91 \%$ of side effects related to the use of magnesium sulfate, and $5.3 \%$ of cases with a severe side effect, including pulmonary edema [29]. Ochsenbein-Kölble et al. demonstrated that atosiban and magnesium sulfate have similar efficiency on the uterine muscle relaxation efficacy in open fetal surgery [30]. We therefore join Ochsenbein-Kölble et al. to recommend that magnesium sulfate should not be used as perioperative tocolytic anymore in fetal surgery.

\subsection{Characteristics of the French population}

One of the major limitations of our study is the small size of our cohort. However, this reflects the sociological characteristics of French population illustrated by a higher rate of termination of pregnancy in case of prenatal diagnosis of MMC. However, in our French national reference center we observed that $77.3 \%$ of the couples who decide to pursue the pregnancy intend to have fetal surgery. We consider as unethical not to propose fetal MMC repair in these cases. On the other hand, one might question the relevance of the presence of more than one center in France for about five cases of fengctal MMC repair per year. Joyeux et al. demonstrated in a recent study that the number of fetal MMC cases operated correlates with the outcome of the MMC fetal closure [31]. 


\subsection{Perspectives of fetal MMC surgery}

Two challenges remain to be addressed: reducing the maternal risks and improving the effectiveness of surgery on the children's prognosis. Fetoscopy may represent a promising approach to reduce the maternal risks, allowing vaginal delivery and reducing the risk of uterine scar dehiscence and uterine rupture in subsequent pregnancies [25,26]. With regards to children's prognosis, the results from the MOM study children follow-up at school age are very encouraging but showed that $71 \%$ are not able to walk without orthotics and $62 \%$ are compelled to perform clean intermittent catheterization [5,21]. Fetal surgery is probably performed at an overly advanced gestational age, when the spinal cord has already been irreversibly damaged [32]. An earlier intervention would seem to be difficult given the timing of prenatal diagnosis, the fetal fragility at earlier gestational age, and the increased risk of PPROM before 24 weeks. It therefore seems necessary to develop adjuvant therapies to improve spinal cord repair at the time of fetal surgery. Stem cell therapy is one of the relevant options and a few teams around the world already have particularly encouraging results in animal models of MMC [33]. 


\section{Acknowledgements}

The authors thank the Clinical Research Unit Paris Descartes Necker Cochin (Rafika Aucourt, Nelly Briand, Jean-Marc Tréluyer, Virginie Vignon, Émilie Le Roux, Virginie Le Guen) for coordination assistance.

The authors thank Dr Olivia Ansellem, Blandine Beauvois, Dr Marianne Besnard, Dr Laurent Bidat, Pauline Bros, Dr Bernard Broussin, Dr Dominique Eyrolle-Guignot, Pr Florent Fuchs, Dr Valérie Goua, Dr Eugénie Jolivet, Dr Hélène Laurichesse, Dr Valérie Mairovitz, Dr Jérôme Massardier, Dr Agnès Sartor, Dr Pascal Vaast, Pr Matthieu Vinchon for referring their patients to our center and/or for their cooperation in retrieving their follow-up data.

\section{Funding}

This research did not receive any specific grant from funding agencies in the public, commercial, or not-for-profit sectors.

Declarations of interest: none 


\section{References}

[1] EUROCAT prevalence chart and tables [Internet]. [accessed 2020 May 20]. Available from: http://www.eurocat-network.eu/accessprevalencedata/ prevalencetables

[2] De Vigan C, Khoshnood B, Lhomme A, Vodovar V, Goujard J, Goffinet F. Prevalence and prenatal diagnosis of congenital malformations in the Parisian population: twenty years of surveillance by the Paris Registry of congenital malformations. J Gynecol Obstet Biol Reprod (Paris). 2005;34(1 Pt 1):8-16., https://doi.org/10.1016/s0368-2315(05)82665-1

[3] Beuriat P-A, Szathmari A, Hameury F, Poirot I, Massoud M, Massardier J, et al. [Changes in the epidemiology of Spina Bifida in France in the last 30 years]. Neurochirurgie. 2017 May;63(2):109_ 11. https://doi.org/10.1016/j.neuchi.2017.01.003

[4] Adzick NS, Thom EA, Spong CY, Brock JW, Burrows PK, Johnson MP, et al. A Randomized Trial of Prenatal versus Postnatal Repair of Myelomeningocele. N Engl J Med. 2011;364(11):993-1004. https://doi.org/10.1056/NEJMoa1014379

[5] Houtrow AJ, Thom EA, Fletcher JM, Burrows PK, Adzick NS, Thomas NH, et al. Prenatal Repair of Myelomeningocele and School-age Functional Outcomes. Pediatrics. 2020;145(2):e20191544. https://doi.org/10.1542/peds.2019-1544

[6] Friszer S, Dhombres F, Di Rocco F, Rigouzzo A, Garel C, Guilbaud L, et al. Preliminary results from the French study on prenatal repair for fetal myelomeningoceles (the PRIUM study). $J$ Gynecol Obstet Biol Reprod (Paris). $2016 \quad$ Sep;45(7):738-44. https://doi.org/10.1016/j.jgyn.2015.09.002.

[7] Maurice P, Garel J, Garel C, Dhombres F, Friszer S, Guilbaud L, et al. New insights in cerebral findings associated with fetal myelomeningocele: a retrospective cohort study in a single tertiary centre. BJOG. 2020 Feb 29. https://doi.org/10.1111/1471-0528.16185.

[8] Moron AF, Barbosa MM, Milani H, Sarmento SG, Santana E, Suriano IC, et al. Perinatal outcomes after open fetal surgery for myelomeningocele repair: a retrospective cohort study. BJOG. 2018;125(10):1280-86. https://doi.org/10.1111/1471-0528.15312

[9] Mamelle N, Munoz F, Grandjean H. Fetal growth from the AUDIPOG study. I. Establishment of reference curves. J Gynecol Obstet Biol Reprod (Paris). 1996;25(1):61-70. PMID: 8901304.

[10] Friszer S, Dhombres F, Morel B, Zerah M, Jouannic JM, Garel C. Limited Dorsal Myeloschisis: A Diagnostic Pitfall in the Prenatal Ultrasound of Fetal Dysraphism. Fetal Diagn Ther. 2017;41(2):136-44. https://doi.org/10.1159/000445995

[11] Zerah M, de Saint Denis T, Garel C, Jouannic JM, Di Rocco F. An intermediate form of dysraphism: the MyeLDM. Childs Nerv Syst. 2020;36(7):1333-34. https://doi.org/10.1007/s00381020-04631-5

[12] Moldenhauer JS, Soni S, Rintoul NE, Spinner SS, Khalek N, Martinez-Poyer J, et al. Fetal myelomeningocele repair: the post-MOMS experience at the Children's Hospital of Philadelphia. Fetal Diagn Ther. 2015;37(3):235-40. https://doi.org/10.1159/000365353

[13] Zamłyński J, Olejek A, Koszutski T, Ziomek G, Horzelska E, Gajewska-Kucharek A, et al. Comparison of prenatal and postnatal treatments of spina bifida in Poland: a non-randomized, single-center study. J Matern-Fetal Neonatal Med. 2014;27(14):1409-1417. https://doi.org/10.3109/14767058.2013.858689

[14] Möhrlen U, Ochsenbein-Kölble N, Mazzone L, Kraehenmann F, Hüsler M, Casanova B, et al. Benchmarking against the MOMS Trial: Zurich Results of Open Fetal Surgery for Spina Bifida. Fetal Diagn Ther. 2020;47(2):91-7. https://doi.org/10.1159/000500049 
[15] Flanders TM, Heuer GG, Madsen PJ, Buch VP, Mackell CM, Alexander EE, et al. Detailed analysis of hydrocephalus and hindbrain herniation after prenatal and postnatal myelomeningocele closure: report from a Single Institution. Neurosurgery. 2020;1;86(5):637-45. https://doi.org/10.1093/neuros/nyz302.

[16] Bowman RM, McLone DG, Grant JA, Tomita T, Ito JA. Spina bifida outcome: a 25-year prospective. Pediatr Neurosurg. 2001 Mar;34(3):114-20. https://doi.org/10.1159/000056005.

[17] Farmer DL, Thom EA, Brock JW 3rd, Burrows PK, Johnson MP, Howell LJ, et al. The Management of Myelomeningocele Study: Full Cohort 30-month Pediatric Outcomes. Am J Obstet Gynecol. 2018;218(2):256.e1-256.e13. https://doi.org/10.1016/j.ajog.2017.12.001

[18] Shurtleff DB, Hayden PW, Chapman WH, Broy AB, Hill ML. Myelodysplasia. Problems of longterm survival and social function. West J Med. 1975 Mar;122(3):199-205.

[19] Clayton DB, Thomas JC, Brock JW 3rd. Fetal repair of myelomeningocele: current status and urologic implications. J Pediatr Urol. 2020;16(1):3-9. https://doi.org/10.1016/j.jpurol.2019.11.019

[20] Macedo A Jr, Ottoni SL, Garrone G, Liguori R, Cavalheiro S, Moron A, et al. In utero myelomeningocoele repair and urological outcomes: the first 100 cases of a prospective analysis. Is there an improvement in bladder function? BJU Int. 2019;123(4):676-81. https://doi.org/10.1111/bju.14639

[21] Brock JW 3rd, Thomas JC, Baskin LS, Zderic SA, Thom EA, Burrows PK, et al. Effect of Prenatal Repair of Myelomeningocele on Urological Outcomes at School Age. J Urol. 2019;202(4):812818. https://doi.org/10.1097/JU.0000000000000334

[22] Johnson MP, Bennett KA, Rand L, Burrows PK, Thom EA, Howell LJ, et al. The Management of Myelomeningocele Study: obstetrical outcomes and risk factors for obstetrical complications following prenatal surgery. Am J Obstet Gynecol. 2016 Dec;215(6):778.e1-778.e9. https://doi.org/10.1016/j.ajog.2016.07.052

[23] Bennett KA, Carroll MA, Shannon CN, Braun SA, Dabrowiak ME, Crum AK, et al. Reducing perinatal complications and preterm delivery for patients undergoing in utero closure of fetal myelomeningocele: further modifications to the multidisciplinary surgical technique. J Neurosurg Pediatr. 2014;14(1):108-14. https://doi.org/10.3171/2014.3.PEDS13266

[24] Goodnight WH, Bahtiyar O, Bennett KA, Emery SP, Lillegard JB, Fisher A, et al. Subsequent pregnancy outcomes after open maternal-fetal surgery for myelomeningocele. Am J Obstet Gynecol. 2019;220(5):494.e1-494.e7. https://doi.org/10.1016/j.ajog.2019.03.008.

[25] Soni S, Moldenhauer JS, Spinner SS, Rendon N, Khalek N, Martinez-Poyer J, et al. Chorioamniotic membrane separation and preterm premature rupture of membranes complicating in utero myelomeningocele repair. Am J Obstet Gynecol. 2016;215(6):778.e1-778.e9. https://doi.org/10.1016/j.ajog.2016.07.052

[26] Kabagambe SK, Jensen GW, Chen YJ, Vanover MA, Farmer DL. Fetal Surgery for Myelomeningocele: A Systematic Review and Meta-Analysis of Outcomes in Fetoscopic versus Open Repair. Fetal Diagn Ther. 2018;43(3):161-74. https://doi.org/10.1159/000479505.

[27] Sanz Cortes M, Lapa DA, Acacio GL, Belfort M, Carreras E, Maiz N, et al. Proceedings of the First Annual Meeting of the International Fetoscopic Myelomeningocele Repair Consortium. Ultrasound Obstet Gynecol. 2019;53(6):855-863. https://doi.org/10.1002/uog.20308

[28] Kohn JR, Rao V, Sellner AA, Sharhan D, Espinoza J, Shamshirsaz AA, et al. Management of Labor and Delivery After Fetoscopic Repair of an Open Neural Tube Defect. Obstet Gynecol. 2018 Jun;131(6):1062-68. https://doi.org/10.1097/AOG.0000000000002577. 
[29] Wilson MS, Ingersoll M, Meschter E, Bodea-Braescu AV, Edwards RK. Evaluating the side effects of treatment for preterm labor in a center that uses "high-dose" magnesium sulfate. Am J Perinatol. 2014;31(8):711-16. https://doi.org/10.1055/s-0033-1358770

[30] Ochsenbein-Kölble N, Krähenmann F, Hüsler M, Meuli M, Moehrlen U, Mazzone L, et al. Tocolysis for in utero Surgery: Atosiban Performs Distinctly Better than Magnesium Sulfate. Fetal Diagn Ther. 2018;44(1):59-64. https://doi.org/10.1159/000478261

[31] Joyeux L, De Bie F, Danzer E, Russo FM, Javaux A, Peralta CFA, et al. Learning curves of open and endoscopic fetal spina bifida closure: a systematic review and meta-analysis. Ultrasound Obstet Gynecol Off J Int Soc Ultrasound Obstet Gynecol. 2019; https://doi.org/10.1002/uog.20389

[32] Ben Miled S, Loeuillet L, Duong Van Huyen JP, Bessières B, Sekour A, Leroy B, et al. Severe and progressive neuronal loss in myelomeningocele begins before 16 weeks of pregnancy. Am J Obstet Gynecol. 2020; 10:S0002-9378(20)30327-6. https://doi.org/10.1016/j.ajog.2020.02.052.

[33] Dugas A, Larghero J, Zerah M, Jouannic JM, Guilbaud L. Cell therapy for prenatal repair of myelomeningocele: A systematic review. Curr Res Transl Med. 2020;S2452-3186(20)30032-5. https://doi.org/10.1016/j.retram.2020.04.004 
Figure 1. Photograph of the hysterotomy

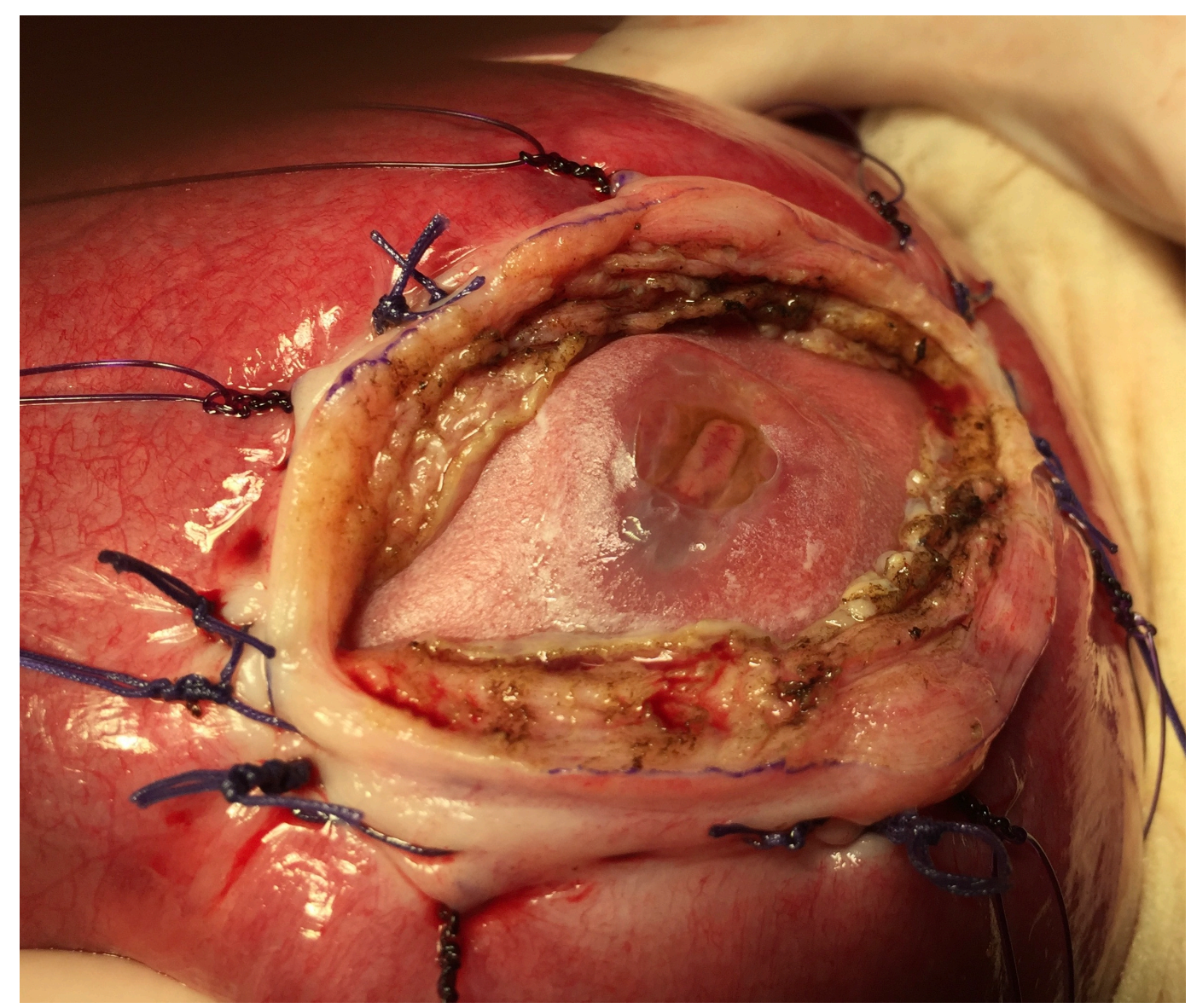


Figure 2. Flow chart

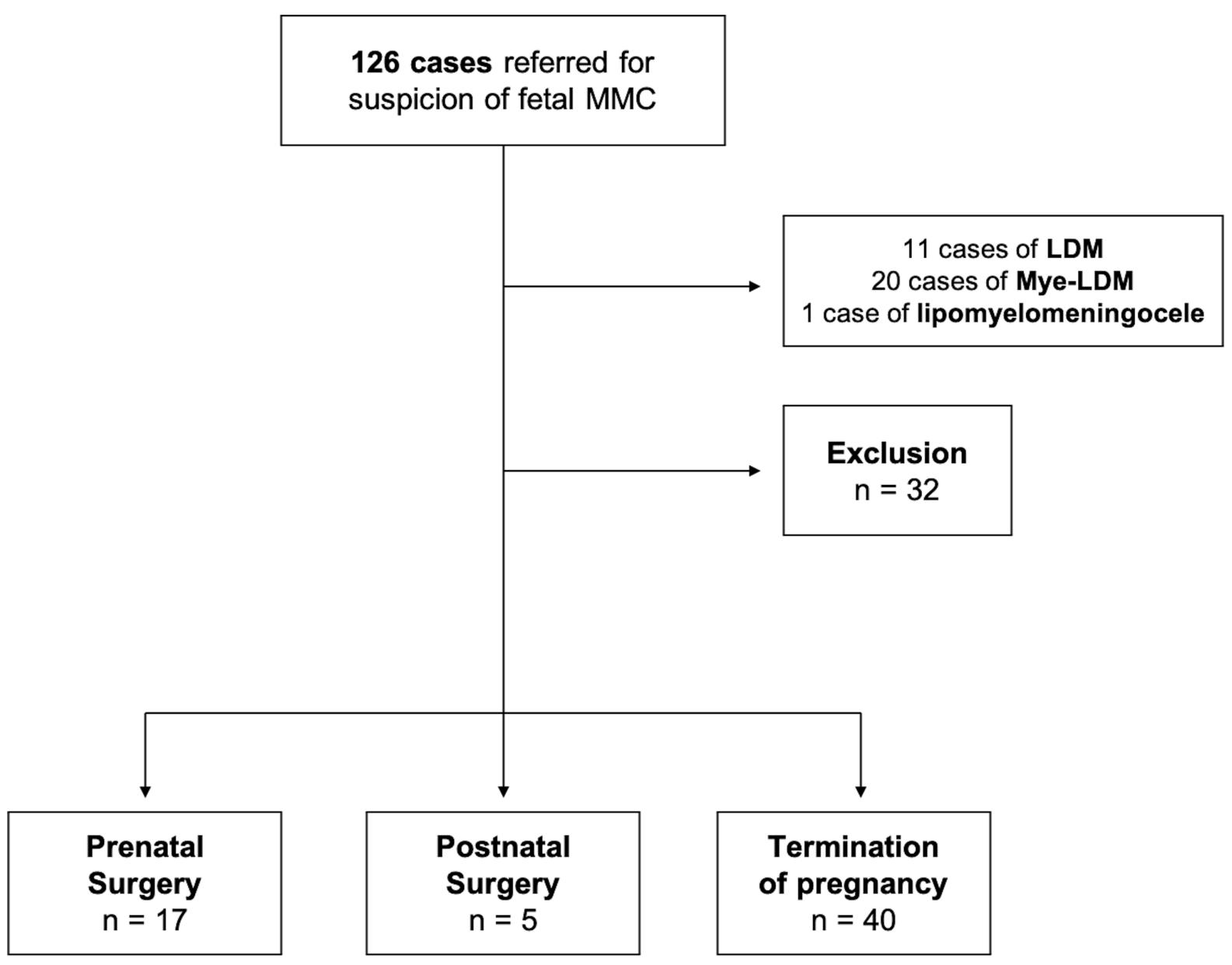


Figure 3. Myelomeningocele level evolution and ability to walk from the prenatal diagnosis to 3 years old after fetal surgery.

Each color corresponds to a case. $\left({ }^{*}\right)$ means that the child is able to walk at the age of 3 , with or without orthotics.

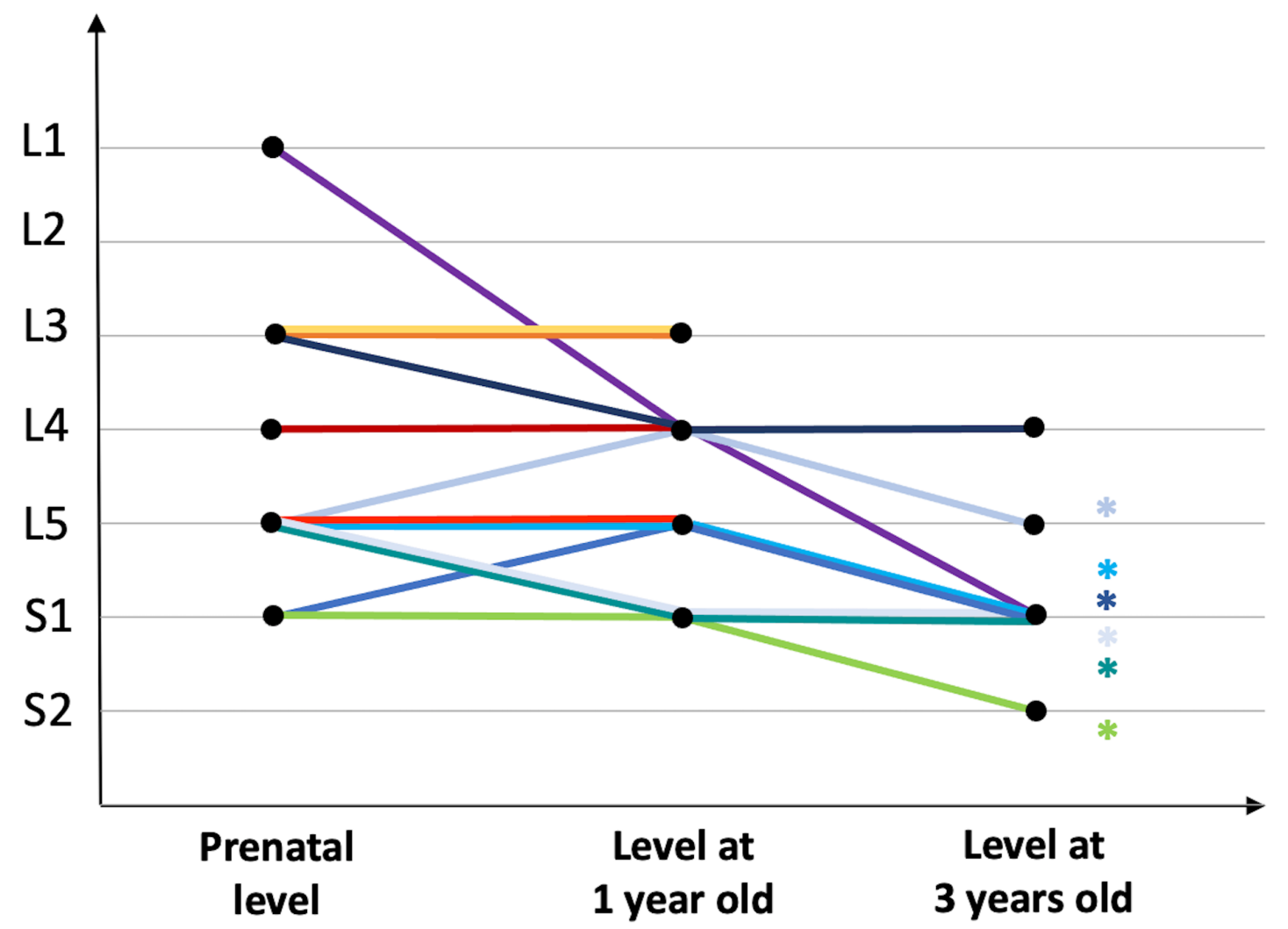


Table 1. Eligible patient for fetal MMC surgery: characteristics

\begin{tabular}{|c|c|c|c|}
\hline & $\begin{array}{c}\text { Prenatal } \\
\text { Surgery } \\
n=17\end{array}$ & $\begin{array}{c}\text { Postnatal } \\
\text { Surgery } \\
n=5\end{array}$ & $\begin{array}{c}\text { Termination of } \\
\text { pregnancy } \\
n=40\end{array}$ \\
\hline Median Maternal age (years) & $29[24-43]$ & $30[23-38]$ & $31[24-44]$ \\
\hline Nulliparous & $4(24 \%)$ & $1(20 \%)$ & $22(55 \%)$ \\
\hline \multicolumn{4}{|l|}{ Ethnicity } \\
\hline Caucasian & $12(70 \%)$ & $1(20 \%)$ & $30(75 \%)$ \\
\hline North African & $2(12 \%)$ & $4(80 \%)$ & $6(15 \%)$ \\
\hline $\begin{array}{l}\text { French overseas } \\
\text { departments/territories }\end{array}$ & $2(12 \%)$ & 0 & $1(2.5 \%)$ \\
\hline Other & $1(6 \%)$ & 0 & $3(7.5 \%)$ \\
\hline Family history of myelomeningocele & 0 & $1(20 \%)$ & $2(5 \%)$ \\
\hline Periconceptional folic acid intake & $3(18 \%)$ & $1(20 \%)$ & $12(30 \%)$ \\
\hline $\begin{array}{l}\text { Median Gestational age at evaluation } \\
\text { (weeks) }\end{array}$ & $22^{+5}\left[14-25^{+2}\right]$ & $22^{+3}\left[20^{+2}-24^{+5}\right]$ & $23\left[15^{+3}-25\right]$ \\
\hline \multicolumn{4}{|l|}{ Fetal gender } \\
\hline Male & $5(30 \%)$ & $3(60 \%)$ & $18(45 \%)$ \\
\hline Female & $12(70 \%)$ & $2(40 \%)$ & $22(55 \%)$ \\
\hline \multicolumn{4}{|l|}{ Lesion level } \\
\hline Thoracic & $1(6 \%)$ & $1(20 \%)$ & $1(2 \%)$ \\
\hline L1/L2 & $2(12 \%)$ & 0 & $9(23 \%)$ \\
\hline L3/L4 & $5(29 \%)$ & $3(60 \%)$ & $12(30 \%)$ \\
\hline L5/S1 & $9(53 \%)$ & $1(20 \%)$ & $18(45 \%)$ \\
\hline \multicolumn{4}{|l|}{ Type of lesion } \\
\hline Myeloschisis & $4(24 \%)$ & $2(40 \%)$ & $11(27 \%)$ \\
\hline Myelomeningocele & $13(76 \%)$ & $3(60 \%)$ & $29(73 \%)$ \\
\hline Ventricle diameter $>10 \mathrm{~mm}$ & $10(59 \%)$ & $2(40 \%)$ & $18(45 \%)$ \\
\hline Corpus callosum abnormalities & $7(41 \%)$ & 0 & $10(25 \%)$ \\
\hline Heterotopia & $3(18 \%)$ & 0 & $2(5 \%)$ \\
\hline Foot deformities & $6(35 \%)$ & $2(40 \%)$ & $10(25 \%)$ \\
\hline
\end{tabular}


Table 2. Maternal and obstetrical outcomes

\begin{tabular}{lc}
\hline PPROM $<37$ weeks & $12(71 \%)$ \\
\hline Preterm labor $<37$ weeks & $8(47 \%)$ \\
\hline Chorioamnionitis & $1(6 \%)$ \\
\hline Placental abruption & $34^{+2}\left[31^{+4}-36^{+6}\right]$ \\
\hline Median gestational age at delivery & 0 \\
\hline Gestational age (weeks) & $10(59 \%)$ \\
$<30$ weeks & $7(41 \%)$ \\
$30-34$ weeks -36 weeks & 0 \\
$>37$ weeks & $14(82 \%)$ \\
Intact & $3(18 \%)$ \\
Thin & 0 \\
\hline Dehiscence & 0 \\
\hline Maternal transfusion &
\end{tabular}


Table 3. Neonatal outcome at birth

\begin{tabular}{|c|c|}
\hline Perinatal death & 0 \\
\hline Median birthweight (g) & $2235[1680-2980]$ \\
\hline Median birthweight (Percentiles) & $48.6[14.3-78.2]$ \\
\hline Median head circumference $(\mathrm{cm})$ & $32[29-36]$ \\
\hline Median head circumference (Percentiles) & $48.8[11-99.9]$ \\
\hline Median Apgar (5 min) & $10[8-10]$ \\
\hline Dehiscence of the MMC scar & 0 \\
\hline Neonatal surgery of the MMC & 0 \\
\hline Respiratory distress syndrome & $7(41 \%)$ \\
\hline Apnea & $3(18 \%)$ \\
\hline Caffeine therapy & $2(12 \%)$ \\
\hline Pneumothorax & $1(6 \%)$ \\
\hline Median length of stay (days) & $20[5-60]$ \\
\hline \multicolumn{2}{|l|}{ Cerebral evaluation } \\
\hline Hindbrain herniation & $7(41 \%)$ \\
\hline Right ventricules & $14.1[9.5-21]$ \\
\hline Left ventricules & $14.5[10-22]$ \\
\hline Ventricle diameter $>15 \mathrm{~mm}$ & $6(35 \%)$ \\
\hline Corpus callosum anomaly & $5(29 \%)$ \\
\hline Heterotopia & $5(29 \%)$ \\
\hline Olfactory sulcus agenesis & $1(6 \%)$ \\
\hline Syringomyelia & $7(41 \%)$ \\
\hline Foot deformities & $12(71 \%)$ \\
\hline
\end{tabular}


Table 4. Children's outcome at 1 year old $(n=12)$

\begin{tabular}{lc}
\hline Need for ventriculo-peritoneal shunt & $3(25 \%)$ \\
\hline Ventricle diameter $>15 \mathrm{~mm}$ & $11(92 \%)$ \\
\hline Hindbrain herniation & $4(33 \%)$ \\
\hline Spine and spinal cord surgery & $1(8 \%)$ \\
\hline Functional vs prenatal lesion level & $1(8 \%)$ \\
1 level better & $6(50 \%)$ \\
$\geq 2$ levels better & $4(33 \%)$ \\
\hline Achilles tenotomy & $1(8.3 \%)$ \\
\hline Orthotics & $2(17 \%)$ \\
\hline Urinary incontinence when crying & $8(67 \%)$ \\
\hline Urinary infections & $9(75 \%)$ \\
\hline Abnormal renal and urinary tract ultrasound & $2(17 \%)$ \\
\hline Anticholinergic treatment & $3(25 \%)$ \\
\hline Bristol score type 1/type 2 & $1(8 \%)$ \\
\hline Osmotic laxative treatment & $3(25 \%)$ \\
\hline
\end{tabular}


Table 5. Children's outcome at 3 years old $(n=8)$

\begin{tabular}{lcc}
\hline \multicolumn{2}{l}{ Need for surgery since 1 year old } & 0 \\
\hline School with a special education assistant & No difference & $8(100 \%)$ \\
\hline Functional versus & 1 level better & $2(25 \%)$ \\
prenatal lesion level & $\geq 2$ levels better & $5(62 \%)$ \\
\hline & Without orthotics & $1(13 \%)$ \\
Walking status & With orthotics & $1(17 \%)$ \\
& Unable to walk & $5(50 \%)$ \\
& (wheelchair) & $2(25 \%)$ \\
\hline Urinary intermittent catheterizations & (prenatal MMC levels: 4 cases L5 and one S1) \\
\hline Wearing diapers & $4(50 \%)$ \\
\hline Urinary infections & $3(38 \%)$ \\
\hline Anticholinergic treatment & $1(13 \%)$ \\
\hline Bristol score type 1/type 2 & $4(50 \%)$ \\
\hline Anal leakage & $5(63 \%)$ \\
\hline Osmotic laxative treatment & $2(25 \%)$ \\
\hline Transanal irrigation & $6(75 \%)$ \\
\hline
\end{tabular}

